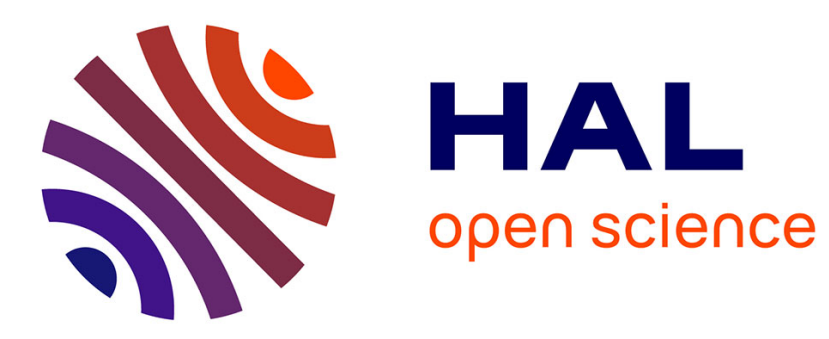

\title{
Digital Platforms as Enablers of Smart Product-Service Systems
}

\author{
Henrique Diogo Silva, António Lucas Soares
}

\section{To cite this version:}

Henrique Diogo Silva, António Lucas Soares. Digital Platforms as Enablers of Smart Product-Service Systems. 22nd Working Conference on Virtual Enterprises (PRO-VE 2021), Nov 2021, Saint-Etienne, France. pp.506-512, 10.1007/978-3-030-85969-5_47 . emse-03346190

\section{HAL Id: emse-03346190 https://hal-emse.ccsd.cnrs.fr/emse-03346190}

Submitted on 25 Nov 2021

HAL is a multi-disciplinary open access archive for the deposit and dissemination of scientific research documents, whether they are published or not. The documents may come from teaching and research institutions in France or abroad, or from public or private research centers.
L'archive ouverte pluridisciplinaire HAL, est destinée au dépôt et à la diffusion de documents scientifiques de niveau recherche, publiés ou non, émanant des établissements d'enseignement et de recherche français ou étrangers, des laboratoires publics ou privés. 
Silva H., Soares A.L. (2021) Digital Platforms as Enablers of Smart Product-Service Systems. In: Camarinha-Matos L.M., Boucher X., Afsarmanesh H. (eds) Smart and Sustainable Collaborative Networks 4.0. PRO-VE 2021. IFIP Advances in Information and Communication Technology, vol 629. Springer, Cham. https://doi.org/10.1007/978-3030-85969-5_47

\title{
Digital Platforms as Enablers of Smart Product-Service Systems
}

\author{
Henrique Silva ${ }^{1}$, António Lucas Soares ${ }^{1,2}$ \\ ${ }^{1}$ INESCTEC, Campus da FEUP, Rua Dr. Roberto Frias s/n, 4200-465 Porto, Portugal \\ ${ }^{2}$ Dep. of Informatics Engineering, Faculty of Engineering, University of Porto, Portugal \\ \{henrique.d.silva@inesctec.pt, antonio.1.soares@inesctec.pt \}
}

\begin{abstract}
The impact of digital technologies in manufacturing organizations has been felt for decades. Servitization processes themselves have developed from the traditional Product-Service Systems (PSS) toward new business models infused with digital technologies, paving the way to smart PSS. There is, however, a lack of understanding of how digital platforms (DP) can be leveraged for the offering of smart service offerings. In this paper, we highlight how the emergence of DP traces the evolution of PSS and highlight how a platformbased modular architecture can serve as the reference infrastructure for organizations to deliver smart and highly customized products and services. The architecture of the Transformer 4.0 platform is used to demonstrate how DP can serve as orchestrators for an ecosystem of digital twin-driven smart PSS.
\end{abstract}

Keywords: Smart Product-Service System; Servitization; Digital Platforms.

\section{Introduction}

The impact of digital technologies in everyday life has been felt for decades [1] In the industrial realm, the Industry 4.0 (i4.0) phenomenon is proof that information technologies (IT) have changed the nature of products and services. While IT started by influencing internal organizational processes optimizing traditional product and service offerings, business model innovation, the emergence of new technologies, and evolving consumer expectations have pushed IT's place outwardly, encouraging companies towards servitization. Even the servitization process itself, that has impacted manufacturing companies for decades, and changed focuses toward new business models based on the bundling of products and services into Product-Service Systems (PSS) has been infused with digital technologies. Authors such as are now arguing for attention to the interplay between digitalization and servitization and how this connection paves the way for PSS embedding digital technologies into smart PSS.

A similar path can be traced for digital platforms (DP). Tracing their lineage to intraorganizational information systems, digital platforms (DP) have grown to become the infrastructure of digital ecosystems that are at the core of how (1) organizations interact in cooperation, coordination and collaboration [2] and (2) in how services are provided to users. Previous studies have begun to suggest how manufacturing firms can leverage a platform approach to overcome some of servitization most common 
problems. There is, however, a lack of understanding in how digital platforms both support the development and selling of advanced, highly customized, smart productservice offerings and how they structure interactions and data flows between actors of the ecosystem.

In this paper, we highlight how the emergence of DP traces the evolution of PSS, focusing on how platform roles, elements of a platform ecosystem, and a platformbased modular architecture, in general, can serve as the reference infrastructure for organizations to deliver smart and highly customized products and services.

\section{Theoretical Background}

The servitization trend of manufacturing firms that shifted from the focus of industrial products to a strategy that provides a combination of products and services has been ongoing for decades [3]. This shift led to the emergence of new business models based, the so-called Product-Service Systems (PSS). Manufacturing organizations adopt a PSS approach to increase their revenues and enhance customer satisfaction [4] by improving efficiency [5] gaining access to new business opportunities and adding differentiation from competitors.

However, in today's highly competitive i4.0 context, a traditional servitization strategy and PSS-based business models do not automatically increase performance. They can even create obstacles that may lead to diminished revenues [6]. Studies such as [7] and [8] have shown that investment in extending service offerings leads to increased costs but frequently lacks in generating the expected higher returns. In fact, in a 2004 survey achieved, only a small percentage (21\%) of firms reached what was considered a financial success after implementing a service strategy, with most companies abandoning their service strategy after a few years. All these factors point to manufacturer's necessity of deploying efficient mechanisms to exploit the benefits of servitization and deliver adapted product and services offerings with a clear strategy and competitive prices while assuring competitive levels of both customization and organizational efficiency.

Recent literature points to how digital technologies help manufacturers improve service offerings and reduce operational costs [9] and in particular, how digitalization and DP allow organizations to configure and deploy service implementations that offer levels of customization at a scale previously not achievable [7]. Although different terms have been used to define what is now more commonly called Smart PSS, a comprehensive definition is presented by [10]. The authors define Smart PSS as "an IT-driven value co-creation business strategy consisting of various stakeholders as the players, intelligent systems as the infrastructure, smart, connected products as the media and tools, and their generated e-services as the key values de-livered, that continuously strives to meet individual customer needs in a sustainable manner". Although, as pointed out by [1] there is still not a commonly agreed conceptual vision and framework for Smart PSS design and implementation, the implied interplay between intelligent digital technologies and service-based business models, is becoming crucial to accomplish a successful servitization model [11]. 
Although earlier conceptualizations of platform view these modular elements as "software products" [12][13](Baldwin et al., 2000; Sanchez \& Mahoney, 1996), others that analyze DP in manufacturing sectors go further into considering "product platforms" as sets of physical components[14][15] or service platforms as sets of "service modules" [16]. On a formal level, [17] and [18] describe plat-form modularity as the decoupling of the platform and its addon functionalities plus the specifications of how these addon systems interact with the platform. This decoupling allows organizations to optimize offerings by: leveraging product and service modules in different offerings [19] allowing for the configuration of several offerings using different combinations of modules [20] and facilitating the creation of pre-defined sets of modules that make up a given service and make the customization process more agile. On the other hand, it is also important to highlight that a modular architecture may also present disadvantages for both the platform and platform-based PSS. On an implementation level, modularity comes at a cost [17], with most of it coming upfront in the platform design stages. This increased difficulty in the architecture design process may lead to significant heterogeneity in offerings [20][16] and not lead to the expected operational efficiencies [21]. On a business level, the literature points to greater levels of modularity leading to an increased risk of imitation by rivals [22] and imposing additional costs on platform addon developers [17]. This cripples the potential development of the platform's ecosystem, hindering the long-term feasibility of the DP [23].

These factors point to the implementation of successful platform-based smart PSS resting primarily not on the anticipation of all requirements and dependencies to achieve a completely modular system but on finding the right balance of modularization for the offering in question. Research has even high-lighted that intermediate levels of modularity produce the most valuable innovations [24] and that how data and information components are handled is a more critical indicator into the successful implementation of advanced service offerings [4].

\section{Digital Platforms for Servitization}

Recent literature has offered two key insights into understanding how the characterization of the complex servitization process has been lacking. Authors such as [4], supported by [25], highlight how a predominant unidirectional view of the product to service continuum has been sup-planted by the customer's need of a full continuum of products and services. [1] direct attention to the interplay between the fields of servitization and digitalization [26][27] looking to the bulk of literature on "digital servitization" starting from 2017 and highlight how the unknowns regarding convergence of digitalization and servitization, the linking between digital servitization and ecosystem management, and the DP impact on digital servitization strategies still outweigh what is found in the literature.

Taken together, these two insights provide a first understanding of how a platformbased approach might serve to alleviate some of the tensions that emerge with servitization. [17] summarizes the characteristics that differentiate platform ecosystems into 
four properties: (i) compressed evolution as the capacity of platforms to shorten the period required to observe different market dynamics; (ii) an evolutionary life cycle process that requires evolution and transformation to survive; (iii) the capacity to harness external disruptions; and (iv) the ability of architecture and governance to shape evolution. As architecture and governance are intrinsically tied in platform environments, shaping the two elements can be leveraged to mold a platform ecosystem's evolution.

The flexibility these four properties embed DP with has positioned them as the preferred infrastructure for developing a new paradigm of business models centered around customers, suppliers, and the developers' aggregation. The resulting ecosystem can generate externalities and synergies where the joint value creation is greater than the sum of the value created by individual businesses [28].

We argue that these four characteristics also play an essential role in implementing business models centered around smart PSS. Taking the perspective of a DP that manages and orchestrates the entire product/service lifecycle, we argue that a compressed evolution capacity allows firms to develop, deploy and validate these highly customized offerings with an efficiency that other infrastructures would not allow for. Furthermore, as described above, the power of modularity comes into play by giving the DP the ability to drop or implement different combinations of products and services according to current business requirements. This allows organizations to harness innovation and constantly develop solutions that can be plugged in with current products and services to improve both returns and efficiency.

The combination of the modularity of physical goods with the layered (and modular) architecture of software gives rise to architectures that, loosely coupled through standardized interfaces, lead to products open for new meanings after manufacture [29][30]. This, in term, pushes the servitization process forward, further away from its linear continuum to an iterative and flexible process where data is gathered from products and services and further contributes to the improvement of the PSS.

\section{Digital Twins Powering Smart PSS - The Transformer 4.0 Case}

Current power transformer development processes are still traditional in nature, relying on document-based information exchange and a set of product lifecycle management (PLM) and simulation tools that are not interconnected. As such, an opportunity presents itself to implement a digital twin-based DP, which will enable the integration of information and data originating in various sources and offer services that streamline power transformer development and add value to the machine beyond its operation and maintenance. Our vision for the Digital Twin (DT) and the DT Enabled DP will be applied to the Power Transformer lifecycle in a Portuguese enterprise of the energy field, effectively shaping its technologies and processes to Industry 4.0 standards.

Based on [17] software four functional elements, the architecture of the Transformer 4.0 (TFR4.0) DP is divided into four components (Fig. 1): a data layer, that comprises both data storage and access, a tools layer, and an interface layer. Connect- 
ing these modular layers three abstraction tools are responsible for the orchestration of all components.

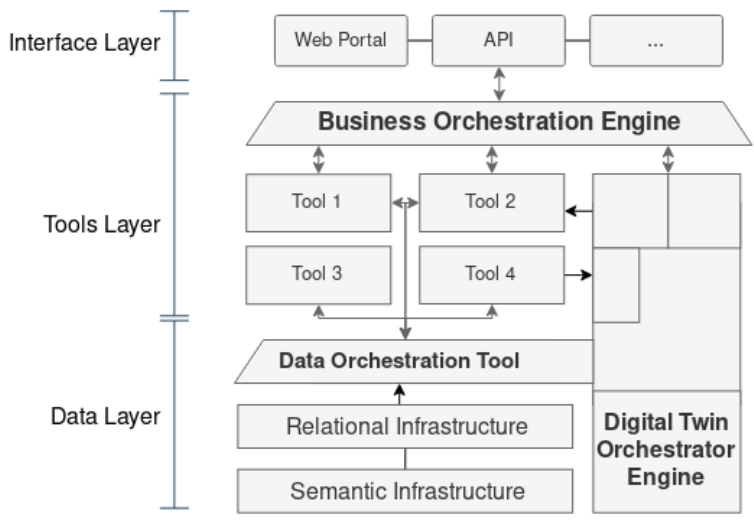

Fig. 1. TRF4.0 platform modular architecture

Placed at the core of the DP, the Digital Twin Orchestrator Engine (DTOE) is a crucial component for the management and orchestration of multiple instances of the DT. A direct link between platform services and the DTOE allows for a shorter latency between platform services and the virtual and physical realities of products/services. This direct link benefits the management of the existing products while facilitating the development and prototyping of new products and services based on the twin. The DTOE is responsible for the dual role of: (i) centralizing the management of the DT components by providing the platform with structured interfaces for direct control, and thus influence both virtual and physical components of multiple instances of a product or service; and (ii) interface with the remaining data layer components to structure and integrate design and operational data and information.

A modular tools layer, built upon the DTOE, leverages the data and information available from the data layer, to deliver the platform's core functionalities. This set of tools ranges from the standard platform services to power the ecosystem, such as user and transaction management, to sets of data-driven tools that fuel the PLM from product development to after-sales servicing. The BOE is responsible for the abstraction and orchestration between the platform's different tools into a coherent set of platform-services. Through the BOE, platform users can leverage and arrange the different modular platform tools into different configurations to test and develop new and innovative, highly customized smart PSS that leverage the full potential of the physical/virtual interaction.

\section{Conclusion}

Although the impacts of technology in the servitization process are not a recent phenomenon, its full extent has not yet been fully realized. The recent focus on digital servitization has started to shed light on how organizations of the future will be able 
to leverage technology to deal with the growing complexity of requirements for customized products and service offerings.

In this paper, we start from an overview of the current literature on servitization to show that, like how DP have grown in many other sectors of the market, a platformbased approach can improve service-product offerings. Through the modularization of the architecture, a DP can gather loosely coupled value of different services into a set of highly customized offerings that fit better fit for different customers.

Furthermore, we present the TRF4.0 case that leverages the benefits of a modular architecture to develop a DP to support a smart PSS business model that generates added value from the entire lifecycle of power transformers. The platform-based approach plays the dual of (i) orchestrating both the multiple instances of the digital twins and the remaining platform services to provide platform users with the capability of developing new offerings, identifying new combinations of products and services and even identify unmet customer needs and new business opportunities; while (ii) serving as the infrastructure for the establishing and managing of a multi-sided business ecosystem that can foster collaboration and innovation between organizations.

The explosion of the platform model has had a profound impact on established business structures. While information-intensive industries were the first to transition to see its effects, technological and business advances will soon convert many of the remaining industries. The integration of PSS business models and digital twin technologies combined with the managed and orchestrated by plat-form-provided tools becomes an important research issue as they become the leading enabler for developing smart products and services throughout the entire life cycle.

From an operational perspective, system design issues, data management, and how traditional user roles can be rearranged become critical for efficiently implementing these systems. In contrast, from a business perspective, how a successful DP can be designed toward evolution in a way that a sustainable business ecosystem can develop should still be the focus of research.

Acknowledgments. The project TRF4p0 - Transformer 4.0 leading to this work is cofinanced by the European Regional Development Fund - ERDF, through COMPETE Operational Program Competitiveness and Internationalization (POCI) and by the Foundation for Science and Technology under the MIT Portugal Program under POCI-01-0247-FEDER-045926.

\section{References}

[1] F. Pirola, C. Cimini, and R. Pinto, "Digital readiness assessment of Italian SMEs: a case-study research," J. Manuf. Technol. Manag., vol. 31, no. 5, pp. 1045-1083, Jan. 2020, doi: 10.1108/JMTM-09-2018-0305.

[2] L. Cremona, A. Ravarini, and J. Sutanto, "KMS in a cluster of firms: The role of a digital platform," in Information Systems, Management, Organization and Control. Lecture Notes in Information Systems and Organisation, vol. 6, Cham: Springer, 2014, pp. 253-262.

[3] F. Beuren, M. Ferreira, and P. Miguel, "Product-service systems: A literature review on integrated products and services," J. Clean. Prod., vol. 47, pp. 222- 
231, May 2013, doi: 10.1016/j.jclepro.2012.12.028.

[4] J. Cenamor, D. Rönnberg Sjödin, and V. Parida, "Adopting a platform approach in servitization: Leveraging the value of digitalization," Int. J. Prod. Econ., vol. 192, pp. 54-65, Oct. 2017, doi: 10.1016/J.IJPE.2016.12.033.

[5] A. Eggert, J. Hogreve, W. Ulaga, and E. Boehm, "Revenue and Profit Implications of Industrial Service Strategies," J. Serv. Res., vol. 17, pp. 2339, Feb. 2014, doi: 10.1177/1094670513485823.

[6] O. Benedettini, M. Swink, and A. Neely, "Examining the influence of service additions on manufacturing firms' bankruptcy likelihood," Ind. Mark. Manag., vol. 60, pp. 112-125, 2017, doi: https://doi.org/10.1016/j.indmarman.2016.04.011.

[7] S. Ransbotham and G. C. (Jerry) Kane, "Membership Turnover and Collaboration Success in Online Communities: Explaining Rises and Falls from Grace in Wikipedia," MIS Q., vol. 35, no. 3, pp. 613-627, Apr. 2011, doi: $10.2307 / 23042799$.

[8] H. Gebauer, E. Fleisch, and T. Friedli, "Overcoming the Service Paradox in Manufacturing Companies,” Eur. Manag. J., vol. 23, no. 1, pp. 14-26, 2005, doi: https://doi.org/10.1016/j.emj.2004.12.006.

[9] D. Kindström and C. Kowalkowski, "Service innovation in product-centric firms: a multidimensional business model perspective," J. Bus. Ind. Mark., vol. 29, no. 2, pp. 96-111, Jan. 2014, doi: 10.1108/JBIM-08-2013-0165.

[10] C. Lerch and M. Gotsch, "Digitalized Product-Service Systems in Manufacturing Firms: A Case Study Analysis," Res. Manag., vol. 58, no. 5, pp. 45-52, Sep. 2015, doi: 10.5437/08956308X5805357.

[11] V. Eloranta and T. Turunen, "Platforms in service-driven manufacturing: Leveraging complexity by connecting, sharing, and integrating," Ind. Mark. Manag., vol. 55, pp. 178-186, 2016, doi: https://doi.org/10.1016/j.indmarman.2015.10.003.

[12] C. Y. Baldwin, K. B. Clark, and K. B. Clark, Design rules: The power of modularity, vol. 1. MIT press, 2000.

[13] D. Sanchez, J. Cavero, and E. Marcos, "The concepts of model in information systems engineering: A proposal for an ontology of models," Knowl. Eng. Rev., vol. 24, no. 1, pp. 5-21, 2009, [Online]. Available: http://www.google.com/search?client=safari\&rls=en-

us\& $\mathrm{q}=$ The + concepts + of + model + in + information + systems + engineering: $+\mathrm{A}+\mathrm{pr}$ oposal+for + an + ontology + of + models \&ie $=U T F-8 \& 0 e=U T F-8$.

[14] F. Salvador, "Toward a Product System Modularity Construct: Literature Review and Reconceptualization," IEEE Trans. Eng. Manag., vol. 54, no. 2, pp. 219-240, 2007, doi: 10.1109/TEM.2007.893996.

[15] B. Huo, C. Zhang, and X. Zhao, "The effect of IT and relationship commitment on supply chain coordination: A contingency and configuration approach," Inf. Manag., vol. 52, no. 6, pp. 728-740, Jun. 2015, doi: 10.1016/j.im.2015.06.007.

[16] C. A. Voss and J. Hsuan, "Service architecture and modularity," Decis. Sci., vol. 40, no. 3, pp. 541-569, 2009.

[17] A. Tiwana, Platform ecosystems: Aligning architecture, governance, and strategy. Newnes, 2013.

[18] A. Tiwana, B. Konsynski, and A. Bush, "Platform evolution: Coevolution of platform architecture, governance, and environmental dynamics," Inf. Syst. Res., vol. 21, no. 4, pp. 675-687, 2010, doi: 10.1287/isre.1100.0323.

[19] M. H. Meyer, E. Jekowsky, and F. G. Crane, "Applying platform design to improve the integration of patient services across the continuum of care," Manag. Serv. Qual. An Int. J., vol. 17, no. 1, pp. 23-40, Jan. 2007, doi: 
$10.1108 / 09604520710720656$.

[20] A. Bask, M. Lipponen, M. Rajahonka, and M. Tinnilä, "The concept of modularity: diffusion from manufacturing to service production," J. Manuf. Technol. Manag., vol. 21, no. 3, pp. 355-375, Jan. 2010, doi: $10.1108 / 17410381011024331$.

[21] A. Bask, M. Lipponen, M. Rajahonka, and M. Tinnilä, "Framework for modularity and customization: service perspective," J. Bus. Ind. Mark., vol. 26, no. 5, pp. 306-319, Jan. 2011, doi: 10.1108/08858621111144370.

[22] S. Ethiraj, D. Levinthal, and R. Roy, "The Dual Role of Modularity: Innovation and Imitation," Manage. Sci., vol. 54, pp. 939-955, May 2008, doi: $10.1287 / \mathrm{mnsc} .1070 .0775$.

[23] H. D. Silva and A. L. Soares, "From Digital Platforms to Ecosystems: A Review of Horizon 2020 Platform Projects," Springer, Cham, 2020, pp. 111120.

[24] S. Ethiraj and D. Levinthal, "Modularity and Innovation in Complex Systems," Manage. Sci., vol. 50, Jan. 2004, doi: 10.2139/ssrn.459920.

[25] T. Baines and H. W. Lightfoot, "Servitization of the manufacturing firm," Int. J. Oper. Prod. Manag., vol. 34, no. 1, pp. 2-35, Jan. 2014, doi: 10.1108/IJOPM-02-2012-0086.

[26] A. G. Frank, G. H. S. Mendes, N. F. Ayala, and A. Ghezzi, "Servitization and Industry 4.0 convergence in the digital transformation of product firms: A business model innovation perspective," Technol. Forecast. Soc. Change, vol. 141, pp. 341-351, 2019, doi: https://doi.org/10.1016/j.techfore.2019.01.014.

[27] T. Paschou, M. Rapaccini, F. Adrodegari, and N. Saccani, "Digital servitization in manufacturing: A systematic literature review and research agenda," Ind. Mark. Manag., vol. 89, pp. 278-292, 2020, doi: https://doi.org/10.1016/j.indmarman.2020.02.012.

[28] S. Yablonsky, "A Multidimensional Framework for Digital Platform Innovation and Management: From Business to Technological Platforms," Syst. Res. Behav. Sci., vol. 35, no. 4, pp. 485-501, Jul. 2018, doi: $10.1002 /$ sres.2544.

[29] M. de Reuver, C. Sørensen, and R. Basole, "The digital platform: A research agenda," J. Inf. Technol., pp. 1-12, 2017, doi: 10.1057/s41265-016-0033-3.

[30] Y. Yoo, O. Henfridsson, and K. Lyytinen, "The new organizing logic of digital innovation: An agenda for information systems research," Inf. Syst. Res., vol. 21, no. 4, pp. 724-735, 2010, doi: 10.1287/isre.1100.0322. 